\title{
Respiratory syncytial virus genotypes NA1, ON1, and BA9 are prevalent in Thailand, 2012-2015
}

\author{
Ilada Thongpan ${ }^{1}$, John Mauleekoonphairoj ${ }^{1}$, Preeyaporn Vichiwattana ${ }^{1}$, Sumeth Korkong ${ }^{1}$, Rujipat

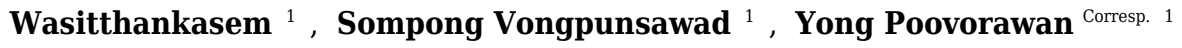 \\ ${ }^{1}$ Center of Excellence in Clinical Virology, Faculty of Medicine, Chulalongkorn University, Bangkok, Thailand \\ Corresponding Author: Yong Poovorawan \\ Email address: Yong.P@chula.ac.th
}

Respiratory syncytial virus (RSV) causes acute lower respiratory tract infection in infants and young children worldwide. To investigate RSV burden in Thailand over four consecutive years (January 2012 to December 2015), we screened 3,306 samples obtained from children $\leq 5$ years old with acute respiratory tract infection using semi-nested reverse-transcription polymerase chain reaction (RT-PCR). In all, $8.4 \%(277 / 3,306)$ of the specimens tested positive for RSV, most of which appeared in the rainy months of July to November. We then genotyped RSV by sequencing the G glycoprotein gene and performed phylogenetic analysis to determine the RSV antigenic subgroup. The majority (57.4\%, 159/277) of the RSV belonged to subgroup A (RSV-A), of which NA1 genotype was the most common in 2012 while ON1 genotype became prevalent the following year. Among samples tested positive for RSV-B subgroup B (RSV-B) (42.6\%, 118/277), most were genotype BA9 $(92.6 \%, 87 / 94)$ with some BA10 and BA-C. Predicted amino acid sequence from the partial $\mathrm{G}$ region showed highly conserved $\mathrm{N}$-linked glycosylation site at residue N237 among all RSV-A ON1 strains (68/68), and at residues N296 (86/87) and N310 (87/87) among RSV-B BA9 strains. Positive selection of key residues combined with notable sequence variations on the $\mathrm{G}$ gene contributed to the continued circulation of this rapidly evolving virus. 


\section{Respiratory syncytial virus genotypes NA1, ON1 and BA9 are prevalent in}

\section{Thailand, 2012-2015}

3

4 Ilada Thongpan ${ }^{1}$, John Mauleekoonphairoj ${ }^{1}$, Preeyaporn Vichiwattana ${ }^{1}$, Sumeth Korkong ${ }^{1}$,

5 Rujipat Wasitthankasem ${ }^{1}$, Sompong Vongpunsawad ${ }^{1}$ and Yong Poovorawan ${ }^{1}$

6

$7{ }^{1}$ Center of Excellence in Clinical Virology, Faculty of Medicine, Chulalongkorn University,

8 Bangkok, Thailand

9

10

11

12

13

14

15

16 Corresponding author:

17 Yong Poovorawan, yong.p@chula.ac.th 
18 ABSTRACT

19 Respiratory syncytial virus (RSV) causes acute lower respiratory tract infection in infants and

20 young children worldwide. To investigate RSV burden in Thailand over four consecutive years

21 (January 2012 to December 2015), we screened 3,306 samples obtained from children $\leq 5$ years

22 old with acute respiratory tract infection using semi-nested reverse-transcription polymerase

23 chain reaction (RT-PCR). In all, 8.4\% (277/3,306) of the specimens tested positive for RSV, most of

24 which appeared in the rainy months of July to November. We then genotyped RSV by

25 sequencing the $\mathrm{G}$ glycoprotein gene and performed phylogenetic analysis to determine the RSV

26 antigenic subgroup. The majority (57.4\%, 159/277) of the RSV belonged to subgroup A (RSV-A),

27 of which NA1 genotype was the most common in 2012 while ON1 genotype became prevalent

28 the following year. Among samples tested positive for RSV-B subgroup B (RSV-B) (42.6\%,

29 118/277), most were genotype BA9 (92.6\%, 87/94) with some BA10 and BA-C. Predicted amino

30 acid sequence from the partial $\mathrm{G}$ region showed highly conserved N-linked glycosylation site at

31 residue N237 among all RSV-A ON1 strains (68/68), and at residues N296 (86/87) and N310

32 (87/87) among RSV-B BA9 strains. Positive selection of key residues combined with notable

33 sequence variations on the $\mathrm{G}$ gene contributed to the continued circulation of this rapidly

34 evolving virus.

35

36

37 


\section{INTRODUCTION}

Human respiratory syncytial virus (RSV) is a major cause of severe respiratory infections in infants and young children (Nair et al., 2010). Although RSV infections in healthy adults are generally limited to the upper respiratory tract, symptoms in infants and children include wheezing, cough, bronchiolitis and pneumonia (Hall, Simoes \& Anderson, 2013). RSV is a member of the newly assigned genus Orthopneumovirus in the family Pneumoviridae (Afonso et al., 2016). It has a single-stranded negative-sense RNA genome of approximately $15.2 \mathrm{~kb}$, which encodes 11 viral proteins (Collins, Fearns \& Graham, 2013). The viral envelope glycoproteins G and $\mathrm{F}$ are important for the receptor attachment and viral fusion with the target cell, respectively. Both surface glycoproteins can induce the host immune response (Wagner et al., 1989). RSV can be divided into two distinct subgroups (RSV-A and RSV-B) (Mufson et al., 1985). Subgroups can be further divided into genotypes based on the gene sequence variability of the second hypervariable region (HVR2) located on the distal third region of the G gene (Melero, Mas \& McLellan 2017). As a result, there are 13 RSV-A genotypes: GA1 to GA7 (Peret et al., 2000), SAA1 (Venter et al., 2001), NA1 to NA4 (Shobugawa et al., 2009; Cui et al., 2013), and ON1 (Eshaghi et al., 2013). To date, 22 RSV-B genotypes are GB1 to GB4 (Peret et al., 2000), SAB1 to SAB4 (Venter et al., 2001; Arnott et al., 2011), URU1 and URU2 (Blanc et al., 2005), BA1 to BA10 (Trento et al., 2006), BA-C (Cui et al., 2013), and THB (Auksornkitti et al., 2014). 
58 in the HVR2. ON1 has since been detected in Europe, Africa, Asia, and the Americas (Cui et al.,

59 2013; Valley-Omar et al., 2013; Pierangeli et al., 2014). Meanwhile, an RSV-B genotype

60 identified in Buenos Aires, Argentina (BA) similarly contained a 60-nucleotide duplication in the

61 HVR2 (Trento et al., 2003). BA has subsequently became so prevalent globally that it largely

62 replaced other RSV-B genotypes (Trento et al., 2010). Gene insertion seen in both RSV-A and

63 RSV-B HVR2 may have affected the antigenicity of the $\mathrm{G}$ protein and enabled viral escape from

64 the host immunity, thus mediating their predominance in recent years.

65 Due to the lack of antivirals or approved vaccines for RSV (Graham \& Anderson, 2013),

66 epidemiological surveillance studies are crucial in understanding RSV transmission and spread.

67 Our previous study described the molecular epidemiology of RSV strains in circulation in

68 Thailand between 2010 and 2011 (Auksornkitti et al., 2014). Here, we characterize recent

69 incidence of RSV infection in Thailand from 2012 to 2015 and examined how the G gene of the

70 circulating strains of RSV are changing, which may explain the persistence of RSV circulation in

71 this region. 
72

73

74

75

76

77

\section{MATERIALS AND METHODS}

\section{Samples}

This study was approved by the Institutional Review Board of the Faculty of Medicine, Chulalongkorn University (IRB 609/59). The need for consent was waived by the IRB since this study involved the use of anonymous residual specimens. In all, 3,306 archived and convenient specimens from January 2012 to December 2015 previously subjected to routine respiratory viral screening in our laboratory were tested for the presence of RSV. These samples comprised nasopharyngeal aspirates, nasal swabs, and throat swabs from individuals $\leq 5$ years of age (mean age 2.4 years, male-to-female ratio of 1 to 0.8 ). Patients presented influenza-like illness (defined as the presence of body temperature $>38^{\circ} \mathrm{C}$ and respiratory tract symptoms such as runny nose, cough, sore throat, and difficulty breathing) or were diagnosed with probable RSV infection by the physicians. Samples were from Bangkok $(\mathrm{n}=1,222$ from King Chulalongkorn Memorial Hospital and Bangpakok 9 International Hospital) and from Khon Kaen province $(\mathrm{n}=2,084$ from Chum Phae Hospital).

RNA extraction, reverse transcription, and PCR amplification

RNA was extracted using the Viral Nucleic Acid Extraction Kit (RBC Bio-science) and cDNA synthesized using an ImProm-II Reverse Transcription System (Promega) according to the manufacturer's instructions. Briefly, RNA and random hexamer primers were incubated at $70^{\circ} \mathrm{C}$ for $5 \mathrm{~min}$, followed by extension for $2 \mathrm{~h}$ at $42^{\circ} \mathrm{C}$ and inactivation at $70^{\circ} \mathrm{C}$ for $15 \mathrm{~min}$. The amplification of the partial G (inclusive of the HVR2) and F genes was performed using semi- 
93 nested PCR as previously described (Auksornkitti et al., 2014). First-round amplification involved

94 initial denaturation at $94^{\circ} \mathrm{C}$ for $3 \mathrm{~min} ; 40$ cycles of denaturation at $94^{\circ} \mathrm{C}$ for $20 \mathrm{~s}$, annealing at

$9555^{\circ} \mathrm{C}$ for $20 \mathrm{~s}$, and elongation at $72^{\circ} \mathrm{C}$ for $90 \mathrm{~s}$; and a final extension at $72^{\circ} \mathrm{C}$ for $10 \mathrm{~min}$. Identical

96 amplification parameters were carried out in the second-round PCR for 30 cycles. The PCR

97 amplicons (approximately 840 bp for RSV-A and 720 bp for RSV-B) were visualized by $2 \%$

98 agarose gel electrophoresis and purified PCR products were sequenced.

99

\section{Sequence comparison and phylogenetic analysis}

101

Nucleotide sequences were visualized using Chromas Lite (v2.01), assembled using

102

SeqMan (DNASTAR), analyzed using the Basic Local Alignment Search Tool (BLAST) program

(http://blast.ncbi.nlm.nih.gov/Blast.cgi), and aligned using BioEdit (v7.0.9.0) and ClustalW. For

genotype assignment, 211 strains of RSV-A $(n=117)$ and RSV-B $(n=94)$ in which the partial

nucleotide sequences for the G gene were successfully obtained were subjected to phylogenetic

analysis. RSV-A strain A2 (genotype GA1, GenBank accession number M74568) and RSV-B

strain B1 (genotype GB1, GenBank accession number AF013254) served as reference strains.

Phylogenetic trees were constructed using the neighbor-joining method implemented in MEGA

(v6.0) with 1,000 bootstrap replicates (Tamura et al., 2013). Differences between (inter-) and

within (intra-) genotypes were evaluated by pairwise nucleotide distance ( $p$-distance) calculations.

All RSV sequences obtained from this study were deposited in the GenBank database under the accession numbers KY327937-KY328054 (RSV-A) and KY328055-KY328148 (RSV-B). 


\section{Predictions of glycosylation sites and positive selection analysis}

115 Deduced amino acid sequences for the partial G gene HVR2 were analyzed for potential

116 N-linked glycosylation sites using the online tool NetNGlyc version 4.0

117 (http://www.cbs.dtu.dk/services/NetNGlyc/). Tests for positive selection were conducted using single-

118 likelihood ancestor counting (SLAC), fixed-effects likelihood (FEL), internal fixed-effects

119 likelihood (IFEL), and random-effects likelihood (REL) models on the Datamonkey server

120 (http:/Www.datamonkey.org), with the ratio of divergence at nonsynonymous and synonymous

121 sites (dN/dS) calculated using the SLAC model. To avoid an excessive false-positive rate, sites

122 with SLAC, FEL and IFEL p-values of $<0.1$ were accepted as under positive selection. Sites with

123 REL Bayesian factors of $>50$ were also accepted as positively selected sites. 


\section{RESULTS}

125

126

127

128

129

130

131

132

133

134

135

136

137

138

139

140

141

142

143

144

\section{RSV prevalence}

In this study, RSV was identified in $8.4 \%(277 / 3,306)$ of all samples tested, of which $57.4 \%$ (159/277) were RSV-A and 42.6\% (118/277) were RSV-B (Table 1). Cyclical pattern was reflected by the predominance of RSV-A in 2012, RSV-B in 2013 and 2014, and the subsequent return of RSV-A predominance in 2015. Co-infection with RSV-A and RSV-B was extremely rare $(0.4 \%$, 1/277). RSV infection appeared to peak in the rainy months of July to November with the highest incidence $(32 \%, 24 / 75)$ in October 2014 (Fig. 1).

\section{Genotyping and phylogenetic analysis}

Analysis of the partial G gene sequence showed that 41\% (48/117) of RSV-A were genotype NA1 (Fig. 2). This genotype was predominant in 2012, but was relatively absent thereafter. An additional 58.1\%(68/117) of RSV-A were ON1, which co-circulated with NA1 in 2012 and remained the only RSV-A genotype detected from 2013 onward. Only one sample was NA3, which appeared in 2012. For RSV-B, most were BA9 (92.6\%, 8794) (Fig. 3). The remainders were BA10 (4.3\%, 4/94) and BA-C (3.2\%, 3/94), which only appeared in 2012 and 2015. One sample (TH-CU448) was co-infected with RSV-A genotype ON1 and RSV-B genotype BA9. For RSV-A, we found an equally high degree of intra-genotype diversity between NA1 and ON1 (Table S1). The $p$-distances within the NA1 and ON1 genotypes ranged from 0.003 to 0.06 (mean $=0.03$ ). In contrast, the inter-genotype $p$-distance between the ON1 and NA1 was lower (0.050), consistent with their close genetic relatedness. For RSV-B, the $p$-distance among 
145 the BA10 strains was 0.010 . However, diversity among the BA9 strains was higher $(p$-distances

146 ranged from 0 to 0.067 ). BA9 and BA10 were more closely related to one another $(p$-distance of

147 0.062) than to BA-C (p-distances of 0.090 and 0.080 , respectively).

148

149 Mutational analysis

150 The predicted amino acid sequences of RSV-A strains obtained in this study corresponded

151 to residue position 212-298 (based on A2 reference strain numbering). As expected, amino acid

152 alignment revealed that all ON1 possessed 24-residue insertion, of which 23 residues are

153 duplication (Fig. 4). Potential N-linked glycosylation site appeared most conserved at N237

154 among all ON1 $(100 \%, 68 / 68)$ and less so for N318 $(94.1 \%, 64 / 68)$, but was absent at N251 and

155 N273. Although most $(87.5 \%, 42 / 48)$ NA1 strains lost the N237 site due to N237D/Y/G

156 substitution, the majority $(62.5 \%, 30 / 48)$ also gained an additional potential glycosylation site at

157 N318. It is noteworthy that NA1 in general possessed either the glycosylation site at N237 or

158 N273, but not both. The lone NA3 identified in this study possessed glycosylation sites at

159 positions N237, N251, and N273.

160 Alignment of RSV-B amino acid sequence with the reference strain B1 revealed an

161 insertion of 20 residues characteristic for the BA genotypes (Fig. 5). Two potential N-linked

162 glycosylation sites, N296 and N310 (based on B1 numbering), were well-conserved in BA9 and

163 BA10, but not BA-C due to T312Y/N substitution. A gain of glycosylation site at N253 was seen

164 in some BA9 strains (TH_CU/B12563/2015 and TH_CU/C5157/2014). 
166 Selection pressure analysis

167 The high substitute rate typically seen in the genes encoding viral surface glycoproteins

168 led us to analyze possible selective pressure on the G gene. Using the SLAC model, we found

169 that the overall $\mathrm{dN} / \mathrm{dS}$ ratios for $\mathrm{NA} 1, \mathrm{ON} 1$, and BA9 were $1.13,1.11$, and 0.65 , respectively

170 (Table 2). Four residues $(233,274,298$, and 314) of ON1 were under selection. Among these, the

171 strongly site-specific P274L and L298P substitutions were identified in at least three selection

172 models. Amino acid position 237 of NA1 and position 244 of BA9 were also likely under

173 positive selection pressure, but these sites were identified only by single selection models. 


\section{DISCUSSION}

175 The muti-year study to investigate the prevalence and genetic diversity of RSV circulating in

176 Thailand was undertaken because of the relative lack of recent prevalence data on RSV infection

177 in this region. The overall frequency of RSV (8.4\%) found in respiratory samples in this study was

178 similar to the rates from previous studies in Thailand of 8.1\% to 8.9\% (Fry et al., 2010; Naorat et

179 al., 2013). The prevalence of RSV in Thailand appears to be moderate and similar to those

180 reported in Senegal (11.4\%) (Fall et al., 2016), Colombia (8.9\%) (Barbosa Ramirez et al., 2014), and

181 the United States (7.7\%) (Fowlkes et al., 2014). Although lower prevalence rates have been

182 reported in Korea (2.7\%) (Noh et al., 2013) and Brazil (2.4\%) (Bellei et al., 2008), RSV infection is

183 reportedly frequent in western China (23.7\%) (Hu et al., 2017), the Philippines (19.3\%-28.1\%) (Ohno

184 et al., 2013; Malasao et al., 2015), Vietnam (23\%) (Yoshida et al., 2010), Indonesia (23\%) (Simões et

185 al., 2011), and Malaysia (18.4\%) (Chan et al., 2002). A recent single hospital study in Laos

186 identified RSV in as many as $41 \%$ of infected children (Nguyen et al., 2017). Unfortunately,

187 objective comparison of the true regional prevalence of RSV is often hindered by the differences

188 in the RSV detection rates largely due to sample size and the period of surveillance among these

189 studies. Nevertheless, it is clear that RSV infection contributes to a significant portion of

190 respiratory tract infection among young children.

191 In our study, RSV-A (57.4\%) occurred more frequently than RSV-B and this observation is

192 consistent with previous reports from other countries (Ohno et al., 2013; Pretorius et al., 2013;

193 Esposito et al., 2015). Several studies including ours have reported alternating epidemics of RSV-

194 A and RSV-B over time (Cui et al., 2013; Ohno et al., 2013; Gilca et al., 2006; Zlateva et al., 
195

196

197

198

199

200

201

202

203

204

205

206

207

208

209

210

211

212

213

2007). This is not surprising since multiple genotypes of RSV-A and RSV-B are known to co-

circulate in a single season and emerging genotypes may replace previously predominant ones in subsequent years (Pretorius et al., 2013). It is hypothesized that the periodic shifts in the predominant RSV subgroup are driven by the dynamics of population immunity and subgroupspecific herd immunity (Botosso et al., 2009), which is analogous to periodic lineage shifts of the influenza B virus over time (Tewawong et al., 2017). Although co-infections by both RSV-A and RSV-B have previously been described in multiple regions (Esposito et al., 2015; Parveen et al., 2006; Kouni et al., 2013), it was relatively rare in our study.

Variability in RSV infection depends on geographical region, season, and year. In

Southeast Asia, RSV incidence appears to peak during the rainy season (July to November), while relatively low rate of infection occurs during the hot and dry months (Arnott et al., 2011;

Nguyen et al., 2017; Yoshida et al., 2010). This is in contrast to the peak incidence in countries with temperate climates whereby RSV infections are more frequent in the winter months (Gilca et al., 2006; Panayiotou et al., 2014; Esposito et al., 2015). For RSV-A, NA1 was the major genotype found in our previous study conducted between 2010 and 2011 (Auksornkitti et al., 2014) and was also seen here in 2012. More recently, ON1 has displaced NA1 to become the predominantly circulating RSV-A strain (Eshaghi et al., 2012; Valley-Omar et al., 2013;

Pierangeli et al., 2014; Kim et al., 2014), although it does not appear to cause more severe disease than other genotypes (Panayiotou et al., 2014; Viegas, Goya \& Mistchenko, 2016). Our 
214 study confirms findings of previous studies in that NA1 and ON1, but not NA3, are frequently

215 identified in Southeast Asia (Arnott et al., 2011; Yoshihara et al., 2016).

216

Between 2012 and 2015, RSV-B genotypes BA9, BA10, and BA-C were frequently

217

218

219

220

221

222

223

224

225

226

227

228

229

230

231

232

233

234

identified. BA9 appeared in Thailand beginning in 2010 and is now the predominant genotype,

while other RSV-B genotypes appeared only sporadically. BA9 and BA10 are commonly

identified in Southeast Asia (Arnott et al., 2011; Tran et al., 2013; Tuan et al., 2015). It is

noteworthy that the BA genotypes, like the ON1, only recently emerged to replace all other RSV-

B strains (Trento et al., 2010). Furthermore, the BA genotypes also possessed duplication in the

HVR2, which is hypothesized to enhance RSV transmissibility by changing the antigenic epitope and facilitate immune evasion (Viegas, Goya \& Mistchenko, 2016).

The relatively high genetic variability associated with the HVR2 was confirmed by the alignment of the predicted amino acid sequences of strains from both RSV subgroups. Of significance was the observed changes in the potential N-linked glycosylation sites, which can alter the antigenic characteristics of the viral surface protein by masking of specific epitopes from the host immunity (Collins \& Graham, 2008; Garcia-Beato et al., 1996). Thus, mutations leading to novel glycosylation sites on viral surface glycoproteins may enable immune evasion. Glycosylation site at N237 was found to be highly conserved in all ON1 strains examined in this study. In contrast, only some NA1 strains possessed N237. A gain in glycosylation at N318 was also observed for some NA1 and ON1. One reason in which NA1 in our study demonstrated more heterogeneity at positions 251 and 318 than in other studies may be attributed to our multiple years of surveillance and larger sample size. The observed variations in the potential $\mathrm{N}$ - 
235 linked glycosylation sites tend to be genotype-specific, and coincidentally most of the positively

236 selected sites in the G protein were in close proximity to and, in some cases, overlapped with,

237 predicted glycosylation motifs (i.e., at amino acid positions 237 and 274). This suggests that

238 positive selection based on $\mathrm{N}$-linked glycosylation sites may play an important role in driving

239 viral diversity (Do et al., 2015) as was shown with residue 274, which is located within an

240 antigenic site and is under positive selection (Eshaghi et al., 2012; Cane, 1997; Ahmed et al.,

241 2016; Malasao et al., 2015). In summary, understanding the genetic variability in the RSV G

242 gene is important in evaluating its evolving pathogenicity and transmission potential.

243

244 CONCLUSION

245 As the G protein of RSV continues to accumulate novel sequence variations, which alter 246 potential N-linked glycosylation patterns and exert positive selection of critical residues, results

247 from this study provide additional knowledge regarding RSV infection pattern and viral diversity 248 crucial for RSV vaccine development. 


\section{ACKNOWLEDGEMENTS}

250 We thank the administrative and laboratory staff of the Center of Excellence in Clinical

251 Virology and King Chulalongkorn Memorial Hospital. 
252

253

254

255

256

257

258

259

260

261

262

263

264

265

266

267

268

269

270

271

272

273

\section{REFERENCES}

Afonso CL, Amarasinghe GK, Bányai K, Bào Y, Basler CF, Bavari S, Bejerman N, Blasdell KR, Briand FX, Briese T, Bukreyev A, Calisher CH, Chandran K, Chéng J, Clawson AN, Collins PL, Dietzgen RG, Dolnik O, Domier LL, Dürrwald R, Dye JM, Easton AJ, Ebihara H, Farkas SL, Freitas-Astúa J, Formenty P, Fouchier RAM, Fù Y, Ghedin E, Goodin MM, Hewson R, Horie M, Hyndman TH, Jiāng D, Kitajima EW, Kobinger GP, Kondo H, Kurath G, Lamb RA, Lenardon S, Leroy EM, Li CX, Lin XD, Liú L, Longdon B, Marton S, Maisner A, Mühlberger E, Netesov SV, Nowotny N, Patterson JL, Payne SL, Paweska JT, Randall RE, Rima BK, Rota P, Rubbenstroth D, Schwemmle M, Shi M, Smither SJ, Stenglein MD, Stone DM, Takada A, Terregino C, Tesh RB, Tian JH, Tomonaga K, Tordo N, Towner JS, Vasilakis N, Verbeek M, Volchkov VE, Wahl-Jensen V, Walsh JA, Walker PJ, Wang D, Wang LF, Wetzel T, Whitfield AE, Xiè J, Yuen KY, Zhang YZ, \& Kuhn JH. 2016. Taxonomy of the order Mononegavirales: update 2016. Archives of Virology 161(8):2351-2360 DOI 10.1007/s00705-016-2880-1.

Ahmed A, Haider SH, Parveen S, Arshad M, Alsenaidy HA, Baaboud AO, Mobaireek KF, AISaadi MM, Alsenaidy AM, Sullender W. 2016. Co-Circulation of 72bp Duplication Group A and 60bp Duplication Group B Respiratory Syncytial Virus (RSV) Strains in Riyadh, Saudi Arabia during 2014. PLoS One 11(11):e0166145 DOI 10.1371/journal.pone.0166145.

Arnott A, Vong S, Mardy S, Chu S, Naughtin M, Sovann L, Buecher C, Beaute J, Rith S, Borand L, Asgari N, Frutos R, Guillard B, Touch S, Deubel V, Buchy P. 2011. A 
study of the genetic variability of human respiratory syncytial virus (HRSV) in Cambodia reveals the existence of a new HRSV group B genotype. Journal of Clinical Microbiology 49(10):3504-3513 DOI 10.1128/JCM.01131-11.

\section{Auksornkitti V, Kamprasert N, Thongkomplew S, Suwannakarn K, Theamboonlers A,} Samransamruajkij R, Poovorawan Y. 2014. Molecular characterization of human respiratory syncytial virus, 2010-2011: identification of genotype ON1 and a new subgroup B genotype in Thailand. Archives of Virology 159(3):499-507 DOI 10.1007/s00705-013-1773-9.

Barbosa Ramirez J, Pulido Dominguez P, Rey Benito G, Mendez Rico J, Castellanos J, Paez Martinez A. 2014. Human respiratory syncytial virus and metapneumovirus in patients with acute respiratory infection in Colombia, 2000 - 2011. Revista Panamericana de Salud Pública 36(2):101-109.

Bellei N, Carraro E, Perosa A, Watanabe A, Arruda E, Granato C. 2008. Acute respiratory infection and influenza-like illness viral etiologies in Brazilian adults. Journal of Medical Virology 80(10):1824-1827 DOI 10.1002jmv.21295.

Blanc A, Delfraro A, Frabasile S, Arbiza J. 2005. Genotypes of respiratory syncytial virus group B identified in Uruguay. Archives of Virology 150(3):603-609.

Botosso VF, Zanotto PM, Ueda M, Arruda E, Gilio AE, Vieira SE, Stewien KE, Peret TC, Jamal LF, Pardini MI, Pinho JR, Massad E, Sant'anna OA, Holmes EC, Durigon EL. 2009. Positive selection results in frequent reversible amino acid replacements in the 
G protein gene of human respiratory syncytial virus. PLOS Pathogens 5(1):e1000254 DOI 10.1371/journal.ppat.1000254.

296

297

298

299

300

301

302

303

304

305

306

307

308

309

310

311

312

313

Cane PA. 1997. Analysis of linear epitopes recognised by the primary human antibody response to a variable region of the attachment $(\mathrm{G})$ protein of respiratory syncytial virus. Journal of Medical Virology 51(4):297-304.

Chan PW, Chew FT, Tan TN, Chua KB, Hooi PS. 2002. Seasonal variation in respiratory syncytial virus chest infection in the tropics. Pediatric Pulmonology 34(1):47-51 DOI 10.1002/ppul.10095

Collins PL, Fearns R, Graham BS. 2013. Respiratory syncytial virus: virology, reverse genetics, and pathogenesis of disease. Current Topics in Microbiology and Immunology 372:3-38 DOI 10.1007/978-3-642-38919-1_1.

Collins PL, Graham BS. 2008. Viral and host factors in human respiratory syncytial virus pathogenesis. Journal of Virology 82(5):2040-2055 DOI 10.1128/JVI.01625-07.

Cui G, Qian Y, Zhu R, Deng J, Zhao L, Sun Y, Wang F. 2013. Emerging human respiratory syncytial virus genotype ON1 found in infants with pneumonia in Beijing, China. Emerging Microbes \& Infections 2(4):e22 DOI 10.1038/emi.2013.19.

Do LA, Wilm A, Van Doorn HR, Lam HM, Sim S, Sukumaran R, Tran AT, Nguyen BH, Tran TT, Tran QH, Vo QB, Dac NA, Trinh HN, Nguyen TT, Binh BT, Le K, Nguyen, MT, Thai QT, Vo TV, Ngo NQ, Dang TK, Cao NH, Tran TV, Ho LV, Farrar J, Jong M, Chen S, Nagarajan N, Bryant JE, Hibberd ML. 2015. Direct 
whole-genome deep-sequencing of human respiratory syncytial virus A and B from

Vietnamese children identifies distinct patterns of inter- and intra-host evolution. Journal of General Virology 96(12):3470-3483.

Eshaghi A, Duvvuri VR, Lai R, Nadarajah JT, Li A, Patel SN, Low DE, Gubbay JB. 2012. Genetic variability of human respiratory syncytial virus A strains circulating in Ontario: a novel genotype with a 72 nucleotide G gene duplication. PloS One 7(3):e32807 DOI 10.1371journal.pone.0032807.

Esposito S, Piralla A, Zampiero A, Bianchini S, Di Pietro G, Scala A, Pinzani R, Fossali E, Baldanti F, Principi N. 2015. Characteristics and Their Clinical Relevance of Respiratory Syncytial Virus Types and Genotypes Circulating in Northern Italy in Five Consecutive Winter Seasons. PloS One 10(6):e0129369 DOI

10.1371/journal.pone.0129369.

Fall A, Dia N, Cisse el HA, Kiori DE, Sarr FD, Sy S, Goudiaby D, Richard V, Niang MN. 2016. Epidemiology and Molecular Characterization of Human Respiratory Syncytial Virus in Senegal after Four Consecutive Years of Surveillance, 2012-2015.PloS One 11(6):e0157163 DOI 10.1371/journal.pone.0157163.

Fowlkes A, Giorgi A, Erdman D, Temte J, Goodin K, Di Lonardo S, Sun Y, Martin K, Feist M, Linz R, Boulton R, Bancroft E, McHugh L, Lojo J, Filbert K, Finelli L. 2014. Viruses associated with acute respiratory infections and influenza-like illness among 
outpatients from the Influenza Incidence Surveillance Project, 2010-2011. The Journal of Infectious Diseases 209(11):1715-1725 DOI 10.1093/infdis/jit806.

335

Fry AM, Chittaganpitch M, Baggett HC, Peret TC, Dare RK, Sawatwong P, Thamthitiwat S, Areerat P, Sanasuttipun W, Fischer J, Maloney SA, Erdman DD, Olsen SJ. 2010. The burden of hospitalized lower respiratory tract infection due to respiratory syncytial virus in rural Thailand. PLoS One 5(11):e15098 DOI 10.1371/journal.pone.0015098.

Garcia-Beato R, Martinez I, Franci C, Real FX, Garcia-Barreno B, Melero JA. 1996. Host cell effect upon glycosylation and antigenicity of human respiratory syncytial virus $\mathrm{G}$ glycoprotein. Virology 221(2):301-309.

Gilca R, De Serres G, Tremblay M, Vachon ML, Leblanc E, Bergeron MG, Dery P, Boivin G. 2006. Distribution and clinical impact of human respiratory syncytial virus genotypes in hospitalized children over 2 winter seasons. The Journal of Infectious Diseases 193(1):54-58.

Graham BS, Anderson LJ. 2013. Challenges and opportunities for respiratory syncytial virus vaccines. Current Topics in Microbiology and Immunology 372:391-404 DOI 10.1007/9783-642-38919-1_20.

Hall CB, Simoes EA, Anderson LJ. 2013. Clinical and epidemiologic features of respiratory syncytial virus. Current Topics in Microbiology and Immunology 372:39-57 DOI 10.1007/978-3-642-38919-1_2. 
352 Hu P, Zheng T, Chen J, Zhou T, Chen Y, Xu X, Pei X. 2017. Alternate circulation and genetic

353

354

355

356

357

358

359

360

361

362

363

364

365

366

367

368

369

370 variation of human respiratory syncytial virus genotypes in Chengdu, West China, 20092014. Journal of Medical Virology 89(1):32-40 DOI 10.1002jmv.24603.

Kim YJ, Kim DW, Lee WJ, Yun MR, Lee HY, Lee HS, Jung HD, Kim K. 2014. Rapid replacement of human respiratory syncytial virus A with the ON1 genotype having 72 nucleotide duplication in G gene. Infection, Genetics and Evolution 26:103-112 DOI 10.1016/j.meegid.2014.05.007.

Kouni S, Karakitsos P, Chranioti A, Theodoridou M, Chrousos G, Michos A. 2013. Evaluation of viral co-infections in hospitalized and non-hospitalized children with respiratory infections using microarrays. Clinical Microbiology and Infection 19(8): 772 777 DOI 10.1111/1469-0691.12015.

Malasao R, Okamoto M, Chaimongkol N, Imamura T, Tohma K, Dapat I, Dapat C, Suzuki A, Saito M, Saito M, Tamaki R, Pedrera-Rico GA, Aniceto R, Quicho RF, SegubreMercado E, Lupisan S, Oshitani H. 2015. Molecular Characterization of Human Respiratory Syncytial Virus in the Philippines, 2012-2013. PLoS One 10(11):e0142192. DOI 10.1371/journal.pone.0142192.

Melero JA, Mas V, McLellan JS. 2017. Structural, antigenic and immunogenic features of respiratory syncytial virus glycoproteins relevant for vaccine development. Vaccine 35(3):461-468 DOI 10.1016/j.vaccine.2016.09.045. 
371 Mufson MA, Orvell C, Rafnar B, Norrby E. 1985. Two distinct subtypes of human respiratory syncytial virus. Journal of General Virology 66(10):2111-2124.

373

374

375

Nair H, Nokes DJ, Gessner BD, Dherani M, Madhi SA, Singleton RJ, O'Brien KL, Roca A, Wright PF, Bruce N, Chandran A, Theodoratou E, Sutanto A, Sedyaningsih ER, Ngama M, Munywoki PK, Kartasasmita C, Simões EAF, Rudan I, Weber MW, Campbell H. 2010. Global burden of acute lower respiratory infections due to respiratory syncytial virus in young children: a systematic review and meta-analysis. Lancet 375(9725):1545-1555 DOI 10.1016/S0140-6736(10)60206-1.

Naorat S, Chittaganpitch M, Thamthitiwat S, Henchaichon S, Sawatwong P, Srisaengchai P, Lu Y, Chuananon S, Amornintapichet T, Chantra S, Erdman DD, Maloney SA, Akarasewi P, Baggett HC. 2013. Hospitalizations for acute lower respiratory tract infection due to respiratory syncytial virus in Thailand, 2008-2011. The Journal of Infectious Diseases 208(Suppl 3):238-245 DOI 10.1093/infdis/jit456.

Nguyen VH, Dubot-Pérès A, Russell FM, Dance DAB, Vilivong K, Phommachan S, Syladeth C, Lai J, Lim R, Morpeth M, Mayxay M, Newton PN, Richet H, De Lamballerie X. 2017. Acute respiratory infections in hospitalized children in Vientiane, Lao PDR - the importance of Respiratory Syncytial Virus. Scientific Reports 7(1):9318 DOI 10.1038/s41598-017-09006-6.

Noh JY, Song JY, Cheong HJ, Choi WS, Lee J, Lee JS, Wie SH, Jeong HW, Kim YK, Choi SH, Han SB, So BH, Kim H, Kim WJ. 2013. Laboratory surveillance of influenza-like 
illness in seven teaching hospitals, South Korea: 2011-2012 season.PloS One 8(5):e64295 DOI 10.1371/journal.pone.0064295.

Ohno A, Suzuki A, Lupisan S, Galang H, Sombrero L, Aniceto R, Okamoto M, Saito M, Fuji N, Otomaru H, Roy CN, Yamamoto D, Tamaki R, Olveda R, Oshitani H. 2013.

Parveen S, Sullender WM, Fowler K, Lefkowitz EJ, Kapoor SK, Broor S. 2006. Genetic variability in the $\mathrm{G}$ protein gene of group A and B respiratory syncytial viruses from India. Journal of Clinical Microbiology 44(9):3055-3064.

\section{Peret TC, Hall CB, Hammond GW, Piedra PA, Storch GA, Sullender WM, Tsou C,} Anderson LJ. 2000. Circulation patterns of group A and B human respiratory syncytial virus genotypes in 5 communities in North America. The Journal of Infectious Diseases 181(6): 1891-1896. 
410

411

412

413

414

415

416

417

418

419

420

421

422

423

424

425

426

427

428

429

Pierangeli A, Trotta D, Scagnolari C, Ferreri ML, Nicolai A, Midulla F, Marinelli K, Antonelli G, Bagnarelli P. 2014. Rapid spread of the novel respiratory syncytial virus A ON1 genotype, central Italy, 2011 to 2013. Eurosurveillance 19(26).

Pretorius MA, van Niekerk S, Tempia S, Moyes J, Cohen C, Madhi SA, Venter M. 2013. Replacement and positive evolution of subtype A and B respiratory syncytial virus Gprotein genotypes from 1997-2012 in South Africa. The Journal of Infectious Diseases 208(Suppl 3):227-237 DOI 10.1093/infdis/jit477.

Shobugawa Y, Saito R, Sano Y, Zaraket H, Suzuki Y, Kumaki A, Dapat I, Oguma T, Yamaguchi M, Suzuki H. 2009. Emerging genotypes of human respiratory syncytial virus subgroup A among patients in Japan. Journal of Clinical Microbiology 47(8):24752482 DOI 10.1128/JCM.00115-09.

Simões EA, Mutyara K, Soh S, Agustian D, Hibberd ML, Kartasasmita CB. 2011. The epidemiology of respiratory syncytial virus lower respiratory tract infections in children less than 5 years of age in Indonesia. The Pediatric Infectious Disease Journal 30(9): 778784 DOI 10.1097/INF.0b013e318218ab9e.

Tamura K, Stecher G, Peterson D, Filipski A, Kumar S. 2013. MEGA6: Molecular Evolutionary Genetics Analysis version 6.0. Molecular Biology and Evolution 30(12):2725-2729 DOI 10.1093/molbev/mst197.

Tewawong N, Suntronwong N, Korkong S, Theamboonlers A, Vongpunsawad S, Poovorawan Y. 2017. Evidence for influenza B virus lineage shifts and reassortants 
430

431

432

433

434

435

436

437

438

439

440

441

442

443

444

445

446

447

448

449

circulating in Thailand in 2014-2016. Infection, Genetics and Evolution 47:35-40 DOI

10.1016/j.meegid.2016.11.010.

Tran DN, Pham TM, Ha MT, Tran TT, Dang TK, Yoshida LM, Okitsu S, Hayakawa S, Mizuguchi M, Ushijima H. 2013. Molecular epidemiology and disease severity of human respiratory syncytial virus in Vietnam. PLoS One 8(1):e45436 DOI 10.1371/journal.pone.0045436.

Trento A, Casas I, Calderon A, Garcia-Garcia ML, Calvo C, Perez-Brena P, Melero JA. 2010. Ten years of global evolution of the human respiratory syncytial virus BA genotype with a 60-nucleotide duplication in the G protein gene. Journal of Virology 84:7500-7512 DOI 10.1128/JVI.00345-10.

Trento A, Galiano M, Videla C, Carballal G, Garcia-Barreno B, Melero JA, Palomo C. 2003. Major changes in the $\mathrm{G}$ protein of human respiratory syncytial virus isolates introduced by a duplication of 60 nucleotides. Journal of General Virology 84(11):31153120.

Trento A, Viegas M, Galiano M, Videla C, Carballal G, Mistchenko AS, Melero JA. 2006. Natural history of human respiratory syncytial virus inferred from phylogenetic analysis of the attachment (G) glycoprotein with a 60-nucleotide duplication. Journal of Virology 80(2):975-984.

Tuan TA, Thanh TT, Hai Nt, Tinh le BB, Kim le TN, Do LA, Chinh B'Krong Nt, Tham NT, Hang Vt, Merson L, Farrar J, Thuong TC, de Jong MD, Schultsz C, van Doorn 
450

451

452

453

454

455

456

457

458

459

460

461

462

463

464

465

466

467

468

HR. 2015. Characterization of hospital and community-acquired respiratory syncytial virus in children with severe lower respiratory tract infections in Ho Chi Minh City, Vietnam, 2010. Influenza and Other Respiratory Viruses 9(3):110-119 DOI

10.1111/irv.12307.

Valley-Omar Z, Muloiwa R, Hu NC, Eley B, Hsiao NY. 2013. Novel respiratory syncytial virus subtype ON1 among children, Cape Town, South Africa, 2012. Emerging Infectious Diseases 19(4):668-670 DOI 10.3201/eid1904.121465.

Venter M, Madhi SA, Tiemessen CT, Schoub BD. 2001. Genetic diversity and molecular epidemiology of respiratory syncytial virus over four consecutive seasons in South Africa: identification of new subgroup A and B genotypes. Journal of General Virology 82(9):2117-2124.

Viegas M, Goya S, Mistchenko AS. 2016. Sixteen years of evolution of human respiratory syncytial virus subgroup A in Buenos Aires, Argentina: GA2 the prevalent genotype through the years. Infection, Genetics and Evolution 43:213-221 DOI 10.1016/j.meegid.2016.04.034.

\section{Wagner DK, Muelenaer P, Henderson FW, Snyder MH, Reimer CB, Walsh EE, Anderson} LJ, Nelson DL, Murphy BR. 1989. Serum immunoglobulin G antibody subclass response to respiratory syncytial virus $\mathrm{F}$ and $\mathrm{G}$ glycoproteins after first, second, and third infections. Journal of Clinical Microbiology 27(3):589-592. 
469 Yoshida LM, Suzuki M, Yamamoto T, Nguyen HA, Nguyen CD, Nguyen AT, Oishi K, Vu 470 TD, Le TH, Le MQ, Yanai H, Kilgore PE, Dang DA, Ariyoshi K. 2010. Viral pathogens associated with acute respiratory infections in central vietnamese children. The

DOI 10.1016/j.meegid.2016.10.010. Pediatric Infectious Disease Journal 29(1):75-77 DOI 10.1097/INF.0b013e3181af61e9.

\section{Yoshihara K, Le MN, Nagasawa K, Tsukagoshi H, Nguyen HA, Toizumi M, Moriuchi H,} Hashizume M, Ariyoshi K, Dang DA, Kimura H, Yoshida LM. 2016. Molecular

evolution of respiratory syncytial virus subgroup A genotype NA1 and ON1 attachment

glycoprotein (G) gene in central Vietnam. Infection, Genetics and Evolution 45:437-446

Zlateva KT, Vijgen L, Dekeersmaeker N, Naranjo C, Van Ranst M. 2007. Subgroup prevalence and genotype circulation patterns of human respiratory syncytial virus in 481 Belgium during ten successive epidemic seasons. Journal of Clinical Microbiology 45(9):3022-3030. 
Figure 1

Seasonal distribution of RSV detected between 2012 and 2015 in this study.

The number of samples examined by month is shown as gray peaks (right scale). RSV positive rates (bar graphs) for RSV-A (black line) and RSV-B (red line) are also shown (left scale).

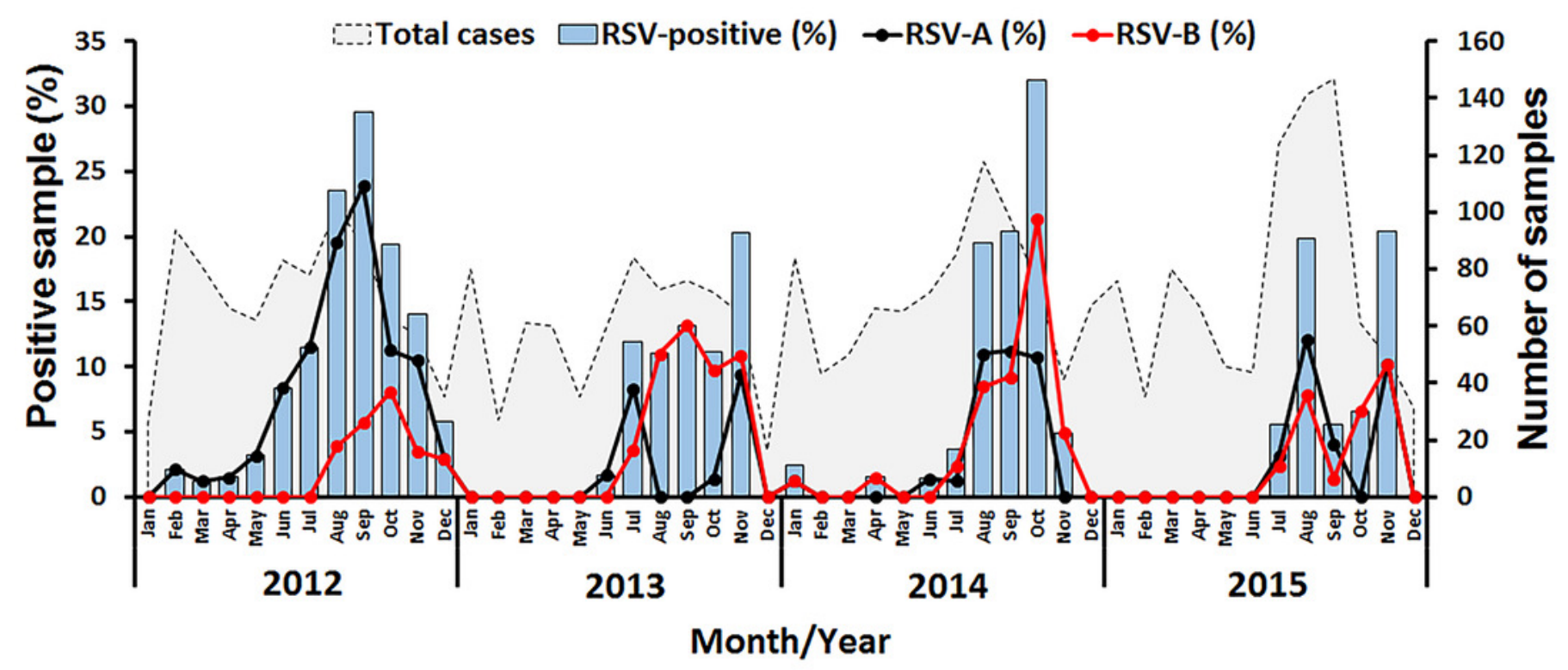




\section{Figure 2}

Phylogenetic tree of RSV-A based on the partial nucleotide sequences of the second hypervariable region (HVR2) of the G gene.

The phylogenetic tree was constructed using the neighbor-joining algorithm in MEGA 6.0 software. Only bootstrap values $>70 \%$ are displayed at the branch nodes. Years of virus isolation are color-coded for 2012 (blue triangle), 2013 (pink diamond), 2014 (green circle), and 2015 (red square). Other genotypes consist of GA1 to GA7, SAA1, NA2 and NA4. The scale bar represents the number of nucleotide substitutions per site between close relatives. The number of strains are in parentheses. 
Thailand strains $\underset{(\mathbf{n}=66)}{2012}$

$\Delta$ Thailand strains 2013
$(\mathbf{n}=8)$

Thailand strains $\underset{(\mathbf{n}=21)}{2014}$

Thailand strains $\underset{(\mathbf{n}=22)}{2015}$
9TH-CU/CB164/2014

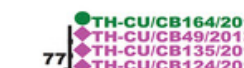

$\mathrm{TH}-\mathrm{CU} / \mathrm{CB} 124 / 2013$
$\mathrm{TH}-\mathrm{CU} / \mathrm{CB} 119 / 2013$
$\mathrm{TH}-\mathrm{CU} / \mathrm{CB} 12212013$ TH-CU/B10980/2014
98 TH-CU/B12696/2015
TH-CU/B12963/201 TH-CU/B12966/2015
TH-CU/B12477/2015
TH.CU/B12568/2015
TH.CU/B12568
TH.CU/B12664/2015

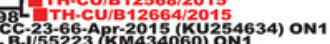
TH-CU/B12405/2015

TH-CU/C6214/2015 (KU254629) ON1 BJ/54609 (KM434057) ON 政H.CU/B12451/2015

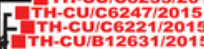
TH-CU/B12797/2015 P TH-CU/C5087/2014 H.TH.CU/C50911/2014

TOTH-CU/B10640/2014 TH-CU/B12563/2015 TH.CU/C3304/2012

Z

TH-CU/C3140/2012

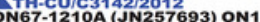

TH.CU/C2860/2012
TH.CU/C 3242/2012 OTH-CU/B10995/2014 PTH-CU/B10625/2014 TH-CU/C5161/2014 TH-CU/B10626/2014 14 (KU254616) ON1 B TH-CUVB1280552015 J/54312 (KM434054) ON1
TH-CU/B12839/2015
TH-CU/B13046/2015 TH-CU/B13046/2015

99 T-TH-CU/C5052/2014 TH-CU/B106331/2014

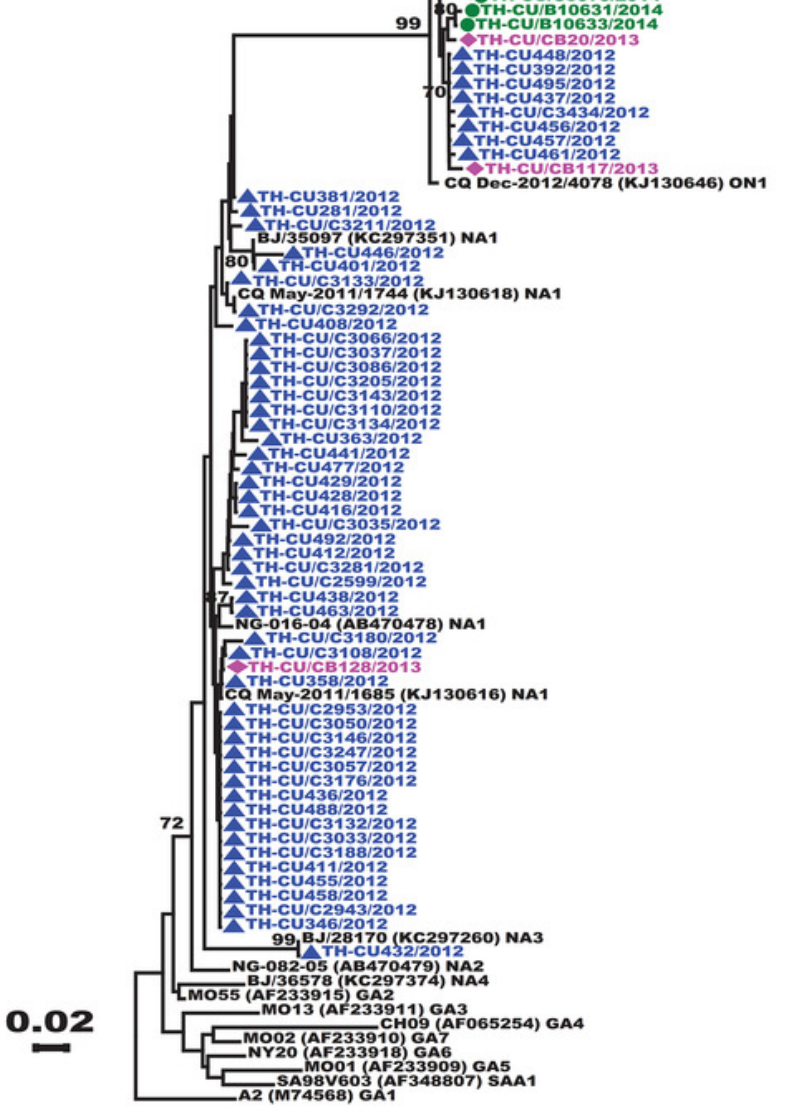

ON1 $(n=68)$

NA1 (n=48) 


\section{Figure 3}

Phylogenetic tree of the RSV-B nucleotide sequences based on the second hypervariable region (HVR2) of the $G$ gene.

The phylogenetic tree was constructed using the neighbor-joining algorithm in MEGA 6.0 software. Bootstrap values $>70 \%$ are displayed at the branch nodes. Years of virus isolation are color-coded for 2012 (blue triangle), 2013 (pink diamond), 2014 (green circle), and 2015(red square). Other genotypes consist of GB1 to GB4, SAB1 to SAB4, URU1, URU2, THB, $B A 1$ to $B A 3, B A 5$ and BA6. The scale bar represents the number of nucleotide substitutions per site between close relatives. The number of strains are in parentheses. 
$\Delta$ Thailand strains $\underset{(\mathrm{n}=19)}{2012}$

$\checkmark T h a i l a n d$ strains 2013

OThailand strains $\underset{(\mathrm{n}=22)}{2014}$

-Thailand strains 2015

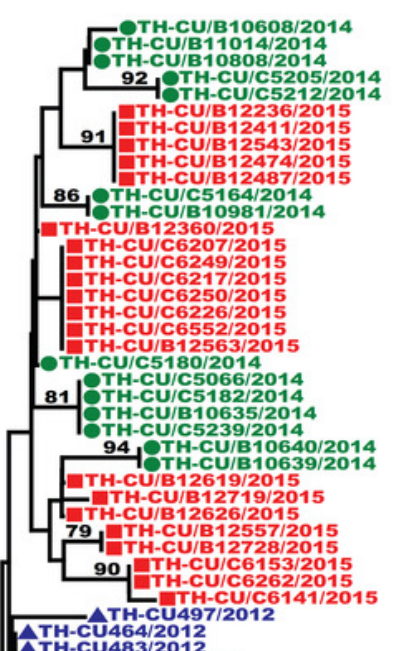

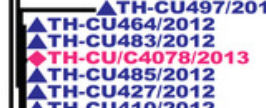

K.TH-CU405/201

A

A TH-CU460/2012

TH-CU/C4149/2013

TH-CU/C4014/2013

THH-CU/C3173/2012

- TH-CU/C4085/2013

TH-CU/C4157/2013

8TH-CU/C5090/2014

TH-CU/CB105/201

- TH-CU/CB127/2013

TH-CU/CB138/2013

TH-CU/CB71/2013

TH-CU/CB129/2013

TH-CU/CB18/2013

TH-CU/CB137/2013

TH-CU448/2012

자-CU/B10596/2014

-OTH-CU/B10985/2014.

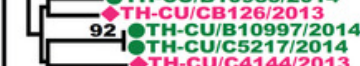

TH-CU/CB112/2013

$\mathrm{TH}-\mathrm{CU} / \mathrm{C} 4051 / 2013$
$\mathrm{TH}-\mathrm{CU} / \mathrm{C} 4066 / 2013$
$\mathrm{TH}-\mathrm{CU} / \mathrm{C} 4065 / 2013$

81

NG-119-07 (HM459878) BA9

LZY90 (GU357515) BA9

81-NTH-CU431/2012

L_NG-068-05 (HM459864) BA7

93 NZL/LJRSV87/20110 (KX765893) BA10

NG-042-07 (HN459884) BA

83 [ 16 -TH-CU/C5097/2015

TH-CU/C5159/2015

-BA/493/04 (DQ227407) BA4

BJ/F9743 (KC297486) BA-C

97 - TH-CU413/2012

8. TH-CU/B12640/2015

0.01

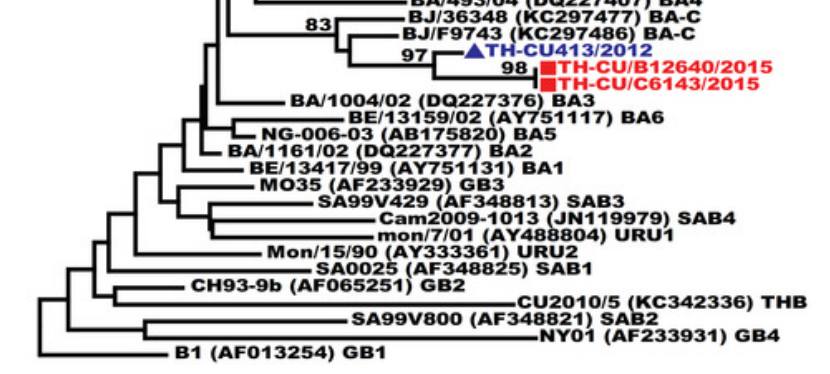

BA9 (n=87)

BA7

$\operatorname{BA10}(n=4)$

BA4

BA-C $(n=3)$

Other genotypes 


\section{Figure 4}

Alignment of the deduced amino acid residues encoding the second hypervariable region (HVR2) of the G protein RSV-A strains identified in this study compared to the reference $A 2$ strain.

The strain genotypes (NA1, ON1, and NA3) are indicated on the right (brackets). The number of additional strains with identical sequence as shown is indicated in parentheses to the right of the strain name. The presence of potential N-linked glycosylation sites are shaded. Asterisks indicate the positions of stop codons. Dots indicate identical residues. Tildes indicate missing residues.

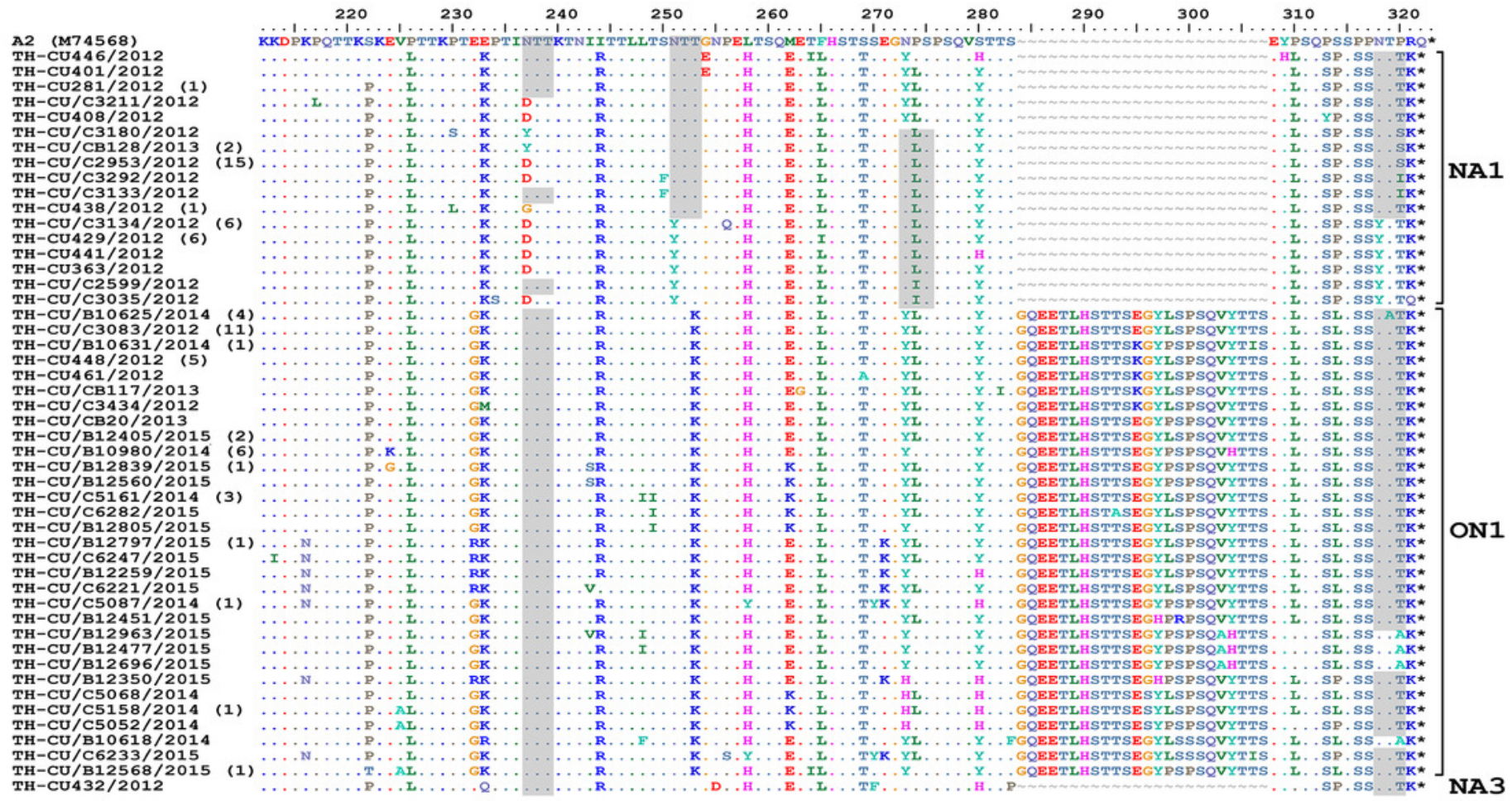




\section{Figure 5}

Alignment of the deduced amino acid residues encoding the second hypervariable region (HVR2) of the G protein RSV-B strains identified in this study compared to the reference B1 strain.

The strain genotypes (BA9, BA10, and BA-C) are indicated on the right (brackets). The number of additional strains with identical sequence as shown is indicated in parentheses to the right of the strain name. The presence of potential N-linked glycosylation sites are shaded. Asterisks indicate the positions of stop codons. Dots indicate identical residues. Tilde indicate missing residues.

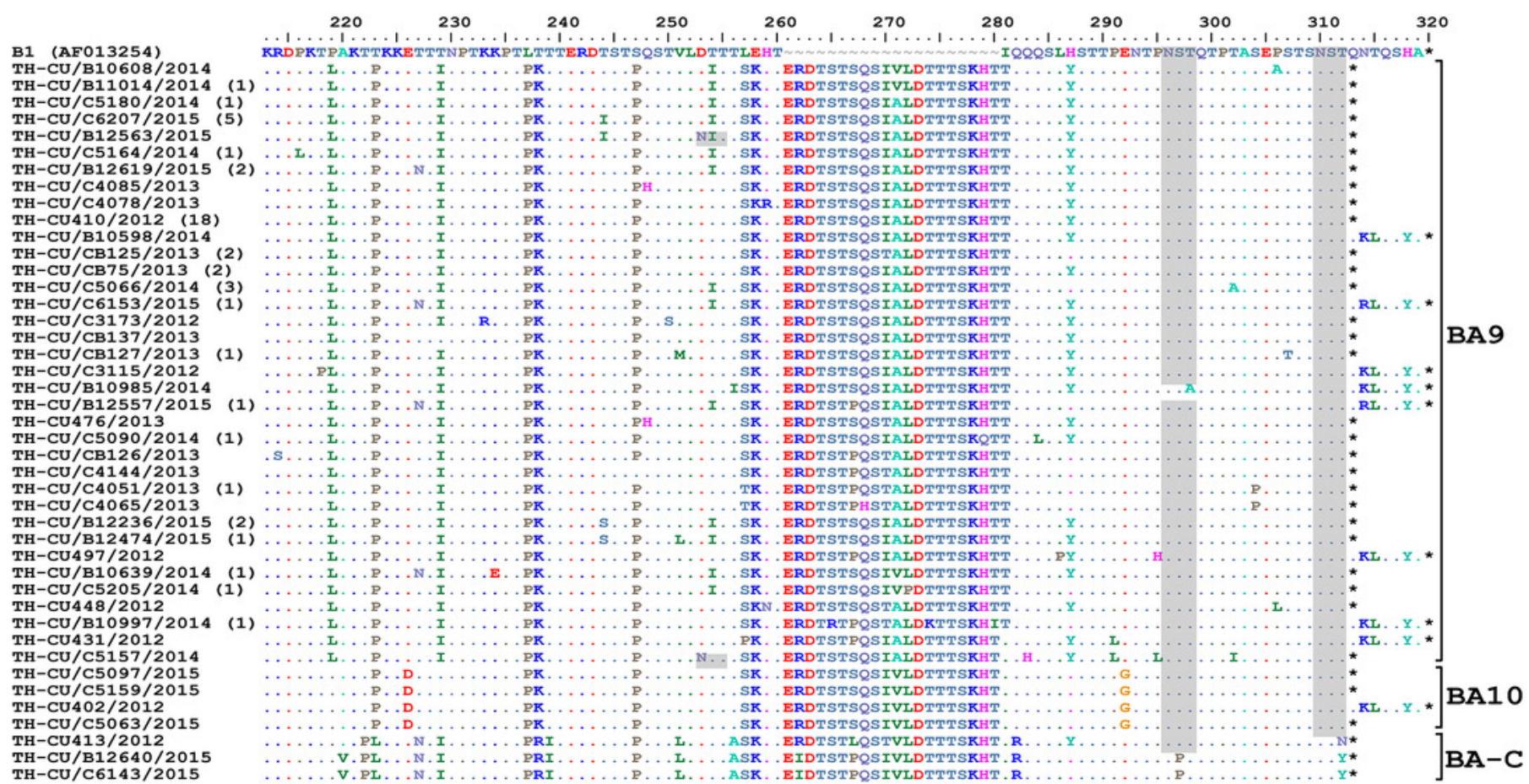




\section{Table $\mathbf{1}$ (on next page)}

RSV identified between 2012 and 2015 from patients with acute respiratory tract infections. 
1 Table 1. RSV identified between 2012 and 2015 from patients with acute respiratory tract

2 infections.

\begin{tabular}{lcccc}
\hline Year & No. of samples & RSV-positive (\%) & \multicolumn{2}{c}{ Groups } \\
\cline { 3 - 5 } & & & $77(81.9)$ & $17(18.1)$ \\
\hline $\mathbf{2 0 1 2}$ & 834 & $94(11.3)$ & $15(30)$ & $35(70)$ \\
$\mathbf{2 0 1 3}$ & 707 & $50(7.1)$ & $35(40.7)$ & $41(59.3)$ \\
$\mathbf{2 0 1 4}$ & 864 & $86(8.8)$ & $32(56.1)$ & $25(43.9)$ \\
Total & 901 & $57(6.3)$ & $\mathbf{1 5 9}(\mathbf{5 7 . 4})$ & $\mathbf{1 1 8}(\mathbf{4 2 . 6 )}$ \\
\hline
\end{tabular}


Table 2 (on next page)

Selection pressure analysis by single-likelihood ancestor counting (SLAC), fixed-effects likelihood (FEL), internal fixed-effects likelihood (IFEL), and random effects likelihood (REL) methods. 
1 Table 2. Selection pressure analysis by single-likelihood ancestor counting (SLAC), fixed-

2 effects likelihood (FEL), internal fixed-effects likelihood (IFEL), and random effects

3 likelihood (REL) methods.

\begin{tabular}{|c|c|c|c|c|c|c|c|c|c|}
\hline \multirow{2}{*}{$\begin{array}{l}\text { Genotype } \\
\text { (Mean } \\
\text { dN/dS ) }\end{array}$} & \multirow[b]{2}{*}{ Codon } & \multicolumn{2}{|c|}{ SLAC } & \multicolumn{2}{|c|}{ FEL } & \multicolumn{2}{|c|}{ IFEL } & \multicolumn{2}{|c|}{ REL } \\
\hline & & $\mathrm{dN} / \mathrm{dS}$ & $p$-value & $\mathrm{dN} / \mathrm{dS}$ & $p$-value & $\mathrm{dN} / \mathrm{dS}$ & $p$-value & $\mathrm{dN} / \mathrm{dS}$ & $\begin{array}{l}\text { Bayesian } \\
\text { factor }\end{array}$ \\
\hline \multirow[t]{3}{*}{ NA1 (1.13) } & 237 & - & - & - & - & - & - & 6.665 & 97643.700 \\
\hline & 273 & - & - & - & - & 66.265 & 0.084 & - & - \\
\hline & 296 & - & - & - & - & 168.21 & 0.078 & - & - \\
\hline \multirow[t]{4}{*}{ ON1 (1.11) } & 233 & - & - & 17.361 & 0.064 & & & 1.778 & 50.153 \\
\hline & $274 *$ & 10.685 & 0.050 & 27.016 & 0.075 & 36.324 & 0.067 & - & - \\
\hline & $298 *$ & 21.605 & 0.002 & 55.119 & 0.012 & 58.489 & 0.023 & 14.822 & 14894.500 \\
\hline & 314 & 8.800 & 0.080 & - & - & & & - & - \\
\hline BA9 (0.65) & 244 & - & - & - & - & 67.675 & 0.040 & - & - \\
\hline
\end{tabular}

4

$5 *$ Indicate strong site-specific substitutions with at least three selection models 6 